\title{
Cell-Based High-Throughput Screening Protocol for Discovering Antiviral Inhibitors Against SARS-COV-2 Main Protease (3CLpro)
}

\author{
Hussin A. Rothan ${ }^{1}$ D. Teow Chong Teoh ${ }^{2}$ \\ Accepted: 2 January 2021 / Published online: 19 January 2021 \\ (c) This is a U.S. government work and not under copyright protection in the U.S.; foreign copyright protection may apply 2021
}

\begin{abstract}
The global public health has been compromised since the severe acute respiratory syndrome coronavirus-2 (SARS-CoV-2) emerged in late December 2019. There are no specific antiviral drugs available to combat SARS-CoV-2 infection. Besides the rapid dissemination of SARS-CoV-2, several variants have been identified with a potential epidemiologic and pathogenic variation. This fact has forced antiviral drug development strategies to stay innovative, including new drug discovery protocols, combining drugs, and establishing new drug classes. Thus, developing novel screening methods and direct-targeting viral enzymes could be an attractive strategy to combat SARS-CoV-2 infection. In this study, we designed, optimized, and validated a cell-based assay protocol for high-throughput screening (HTS) antiviral drug inhibitors against main viral protease (3CLpro). We applied the split-GFP complementation to develop GFP-split-3CLpro HTS system. The system consists of GFP-based reporters that become fluorescent upon cleavage by SARS-CoV-2 protease 3CLpro. We generated a stable GFPsplit-3CLpro HTS system valid to screen large drug libraries for inhibitors to SARS-CoV-2 main protease in the bio-safety level 2 laboratory, providing real-time antiviral activity of the tested compounds. Using this assay, we identified a new class of viral protease inhibitors derived from quinazoline compounds that worth further in vitro and in vivo validation.
\end{abstract}

Keywords SARS-CoV-2 $\cdot$ Protease $\cdot$ GFP complementation $\cdot$ High-throughput screening $\cdot$ Drug libraries

\section{Introduction}

COVID-19 is a pandemic disease caused by SARS-CoV-2, a highly contagious coronavirus causing significant healthcare and economic burden. SARS-CoV-2 is causing a spectrum of disease from asymptomatic to severe complications, including pneumonia, acute respiratory distress syndrome (ARDS), acute lung injury (ALI), cytokine storm syndrome (CSS), and death [1-4]. There are no specific antiviral drugs or vaccines with proven clinical efficacy for treating or preventing infection with SARS-CoV-2, except a few non-specific repurposing drugs [5-7]. Furthermore, several variants of SARS-CoV-2 have been identified with

Hussin A. Rothan

hrothan@gsu.edu

Teow Chong Teoh

ttchong@um.edu.my

1 Department of Biology, College of Arts and Sciences, Georgia State University, Atlanta, GA, USA

2 Institute of Biological Sciences, Faculty of Science, University of Malaya, 50603 Kuala Lumpur, Malaysia potential epidemiologic and pathogenic variation [8-13]. As such, the development of novel antiviral screening methods and direct-targeting of viral enzymes could be an attractive strategy to combat SARS-CoV-2 infection.

SARS-CoV-2 polyproteins are processed by two viral proteases, papain-like protease (PLpro) and 3C-like protease (3CLpro), which are excellent targets for the development of therapeutic antivirals $[14,15]$. Because of its highly conserved sequence, 3CLpro and PLpro have been considered as potential targets for antiviral drugs against SARS, MERS, and COVID-19 [16, 17]. Further, 3CLpro is responsible for virus-induced apoptotic signal [18], and PLpro for stripping ubiquitin and ISG15 from host-cell proteins to aid coronaviruses in their evasion of the host innate immune responses [14]. Therefore, targeting 3CLpro and PLpro may have advantages in inhibiting viral replication and dysregulation of signaling cascades in infected cells.

Viral 3CLpro [also called main protease $\left(\mathrm{M}^{\mathrm{pro}}\right)$ ] cleaves viral polyproteins at 11 sites compared to 3 sites of PLpro [19]. As such, we concentrated our efforts on identifying antiviral candidates against viral 3CLpro. This protease has an identical sequence among coronaviruses and has 
no human homolog [20, 21]. In this study, we developed a protocol for high-throughput screening (HTS) to identify inhibitors against SARS-CoV-2 proteases based on the splitGFP complementation method. Our previous published data showed a practical implementation of split-GFP complementation assay to measure protein translocation from ERto-cytosol [22]. This cell-based-screening protocol is very significant in enhancing the safety, throughput, and reproducibility of antiviral screening. It can be used in biosafety level two laboratory, providing a real-time activity of tested compounds of large drug libraries, and also provide insight on compounds cytotoxicity.

\section{Results and Discussion}

\section{Design GFP-Split-3CLpro Screening Assay}

We designed a cell-based assay using GFP-split complementation to screen drug libraries and identify inhibitors against SARS-CoV-2 main protease 3CLpro. The GFP-split complementation assay was previously designed to measure caspase activity in the apoptotic cells in vitro and in vivo $[23,24]$. We previously used the GFP-split complementation to establish cell lines stably expressing a dislocation-induced reconstituted GFP reporter to monitor and quantify protein translocation from the endoplasmic reticulum to the cytosol [22]. In this study, we utilized this technology to develop and optimize a protocol for high-throughput screening (HTS) to identify inhibitors against SARS-CoV-2 protease by screen small molecules library. We found that this assay is a simple and practical strategy to screen large drug libraries for protease inhibitors.

The assay principle depends on splitting GFP into two units (GFP $\beta 1-9$ and $\beta 10-11$ ), resulting in losing its fluorescent capacity. $\beta 10-11$ has a high affinity to bind to the $\beta 1-9$ and rapidly develops green fluorescence [25]. Thus, split-GFP protease assay depends on preventing GFP units' assembly and making the triggering GFP assembly under protease activity. GFP gains the green fluorescence when $\beta 10$ and $\beta 11$ in anti-parallel position bind to $\beta 1-9$ (Fig. 1a). Using E5/K5 heterodimer to flip $\beta 10$ and $\beta 11$ in parallel form prevents self-assembly of the split GFP (Fig. 1b). Upon protease cleavage, $\beta 11$ flips back, forming an anti-parallel structure with $\beta 10$, which enables self-assembly with $\beta 1-9$ and leads to gain of green fluorescence (Fig. 1c). Insertion of the 3CLpro cleavage site between E5/K5 heterodimer and $\beta 11$ allows the 3CLpro to release $\beta 11$ and to resume the antiparallel structure with $\beta 10$.

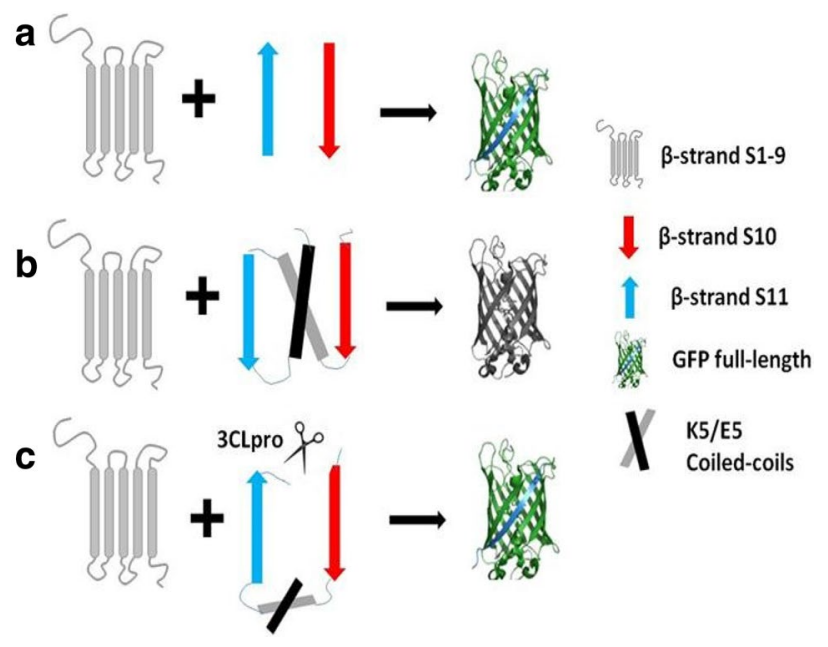

Fig. 1 GFP-split complementation method. This assay was developed as previously described $[23,24]$. Split GFP into $\beta 1-9$ and $\beta 10-11$ resulted in losing its fluorescent capacity. $\beta 10-11$ has a high affinity to bind to the $\beta 1-9$ and rapidly develop green fluorescence [25]. a GFP gains the green fluorescence when $\beta 10$ and $\beta 11$ in anti-parallel position bind to $\beta 1-9$. b E5/K5 heterodimer was used to flip $\beta 10$ and $\beta 11$ in parallel form prevents self-assembly of the split GFP. $\mathbf{c}$ Upon protease cleavage, $\beta 11$ flips back, forming an anti-parallel structure with $\beta 10$, which enables self-assembly with $\beta 1-9$ and gains green fluorescence. The 3CLpro cleaves between E5/K5 heterodimer and $\beta 11$ allowing $\beta 11$ to form the anti-parallel structure with $\beta 10$ (Color figure online)

\section{Development and Optimization of GFP-Split-3CLpro Screening Protocol}

We named this reporter assay a GFP-split-3CLpro assay. We designed and generated an expression cassette consists of two plasmids. The first plasmid harbors GFP construct, and the second plasmid harbors 3CLpro to co-express in HEK293 cells (Fig. 2). We used standard PCR to amplify the two GFP fragments, $\beta$-strand $1-9$ and $\beta$-strand $10-11$. The ten amino acid linker and cleavage sites of 3CLpro and E5/K5 amino acid sequences were inserted into the GFP construct using overlap-extension PCR as we described previously [26] (Fig. 2a). GFP expression was detected at $24 \mathrm{~h}$, and high GFP expression was observed at 48 and $72 \mathrm{~h}$ post-transfection. No considerable GFP expression was observed before the transfection of HEK239T cells with 3CLpro plasmid. The cells transfected only with the GFP construct but not 3CLpro did not show fluorescence activity five days after transfection. The GFP fluorescence dramatically increased at 48 and 72 h, as in Fig. 2b, leading to an increase in the signal-to-noise ratio. We further investigated the expression levels of GFP construct and 3CLpro by immunoblotting. We found higher expression of GFP construct than 3CLpro (Data not shown) that needs extensive plasmid ratio optimization. Increased 3CLpro expression resulted in rapid cleavage into the GFP 
Fig. 2 The expression cassettes of GFP-split-3CLpro assay. The HEK293T cells were co-transfected with the recombinant pcDNA3.1 plasmids, and the GFP fluorescence intensities were measured at 24,48 , and $72 \mathrm{~h}$. a The expression cassette one consists of two plasmids, the first plasmid harbors GFP construct, and the second plasmid harbors SARS-CoV-2 main protease (3CLpro). b GFP fluorescence noticeably increased at 48 and $72 \mathrm{~h}$, leading to an increase in the signal-to-noise ratio. c The expression cassette two consists of two plasmids, the first plasmid expresses the GFP $\beta$-strand 1-9, and the second plasmid harbors a construct of $\beta$-strand 10-11 that was joined to the $\mathrm{C}$-terminus of 3CLpro by another 3CLpro cleavage site to facilitate auto-cleavage of the $\beta$-strand 10-11. dA stable increase in the GFP fluorescent activity initiated when the $\beta$-strand 10-11 released from 3CLpro by enzyme auto-cleavage activity and binds to $\beta$-strand 1-9

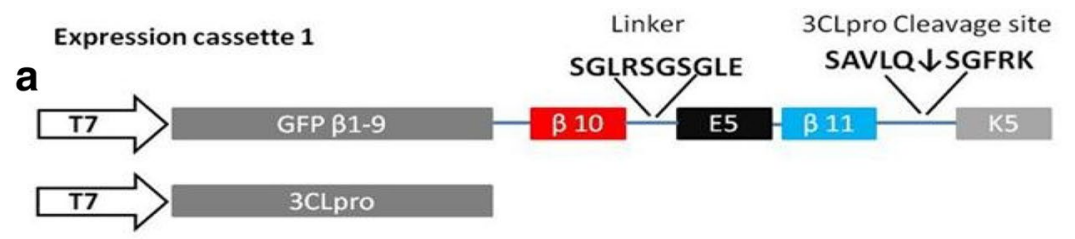

b
$12 \mathrm{~h}$

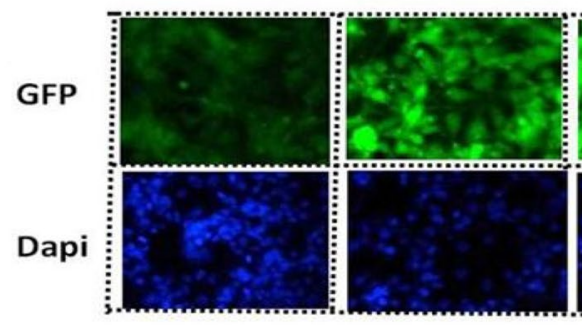

C

Expression cassette 2
$48 \mathrm{~h}$

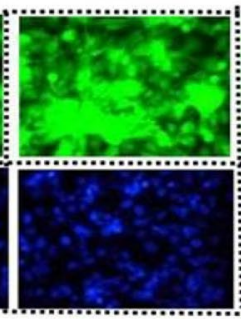

$72 \mathrm{~h}$
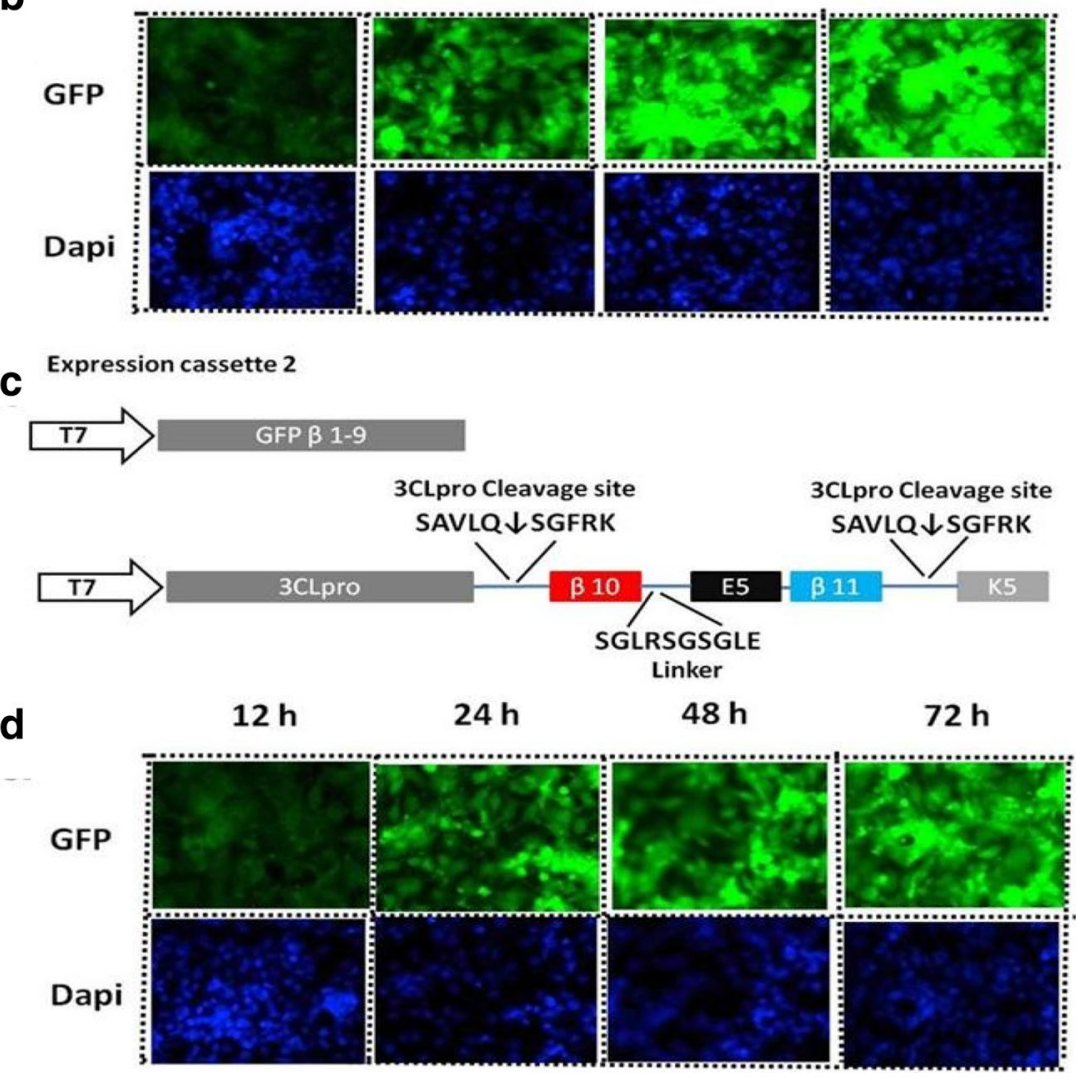

construct and producing high GFP fluorescence. Instead of optimizing plasmid ratios and establishing a stable fluorescent signal, we sought to link the expression levels of GFP to the 3CLpro by generating the expression cassette 2 (Fig. 2c). We joined the $\beta$-strand 10-11 construct to the C-terminus of 3CLpro and inserted another 3CLpro cleavage site to facilitate the release of the $\beta$-strand 10-11. GFP assembly was initiated only when the $\beta$-strand 10-11 released from 3CLpro by enzyme auto-cleavage (Fig. 3). A more stable increase in the GFP fluorescence and optimal signal-to-noise ratio were observed for expression cassette two as compared to cassette one. We evaluated the enzyme activity over time by measuring the GFP fluorescence intensity. In Fig. 3, the $\mathrm{X}$ axis plots the time and the $\mathrm{Y}$ axis plots the GFP intensity. We used the sigmoidal curve

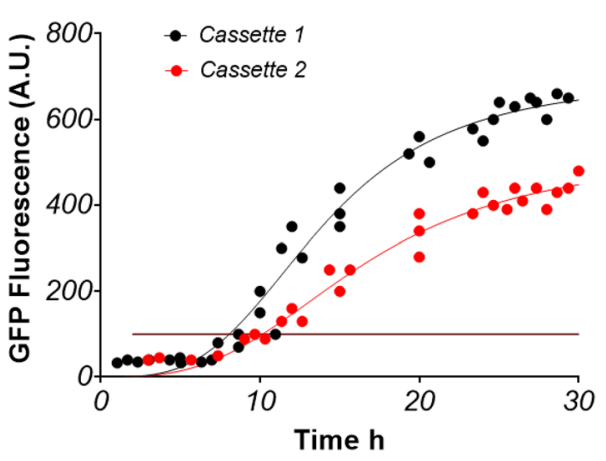

Fig. 3 GFP signal intensities of the expression cassette one and two of GFP-split-3CLpro assay. GFP fluorescence intensities were measured using Tecan F200 Pro multimode microplate reader at excitation $488 \mathrm{~nm}$ and emission $525 \mathrm{~nm}$ at different time points for $30 \mathrm{~h}$ post-transfection 
model to plot the time-enzyme activity relationship, and the continuous lines represent the best-fit values.

\section{Evaluation of GFP-Split-3CLpro Assay By Screening a Small Molecules Library}

Developing an HTS assay for screening thousands of compounds requires extensive optimization and evaluation to verify that the assay is performing acceptably. We evaluated our GFP-split-3CLpro protocol by screening an in-house library of 50 small molecule compounds (Fig. 4a). Most of the compounds possess potential antiviral protease activity based on our previous studies of testing these compounds against NS3-4A protease of the Hepatitis C virus [27], NS2B-NS3 protease of dengue virus [28-36], and NS2BNS3 protease Zika virus [37, 38].

In this study, boceprevir was used as a reference compound that showed a significant reduction in GFP fluorescent activity, suggesting potent inhibition against SARS-CoV-2 main protease (Fig. 4b). This finding agrees with a previous study that showed potent inhibition of boceprevir against SARS-CoV-2 in vitro [39]. Surprisingly, the quinazoline derivatives caused a slight to a significant reduction in GFP fluorescence intensity (Fig. 4c-4g). The compounds QZ1, QZ2, QZ3, and QZ5, showed 20-40\% inhibition of viral
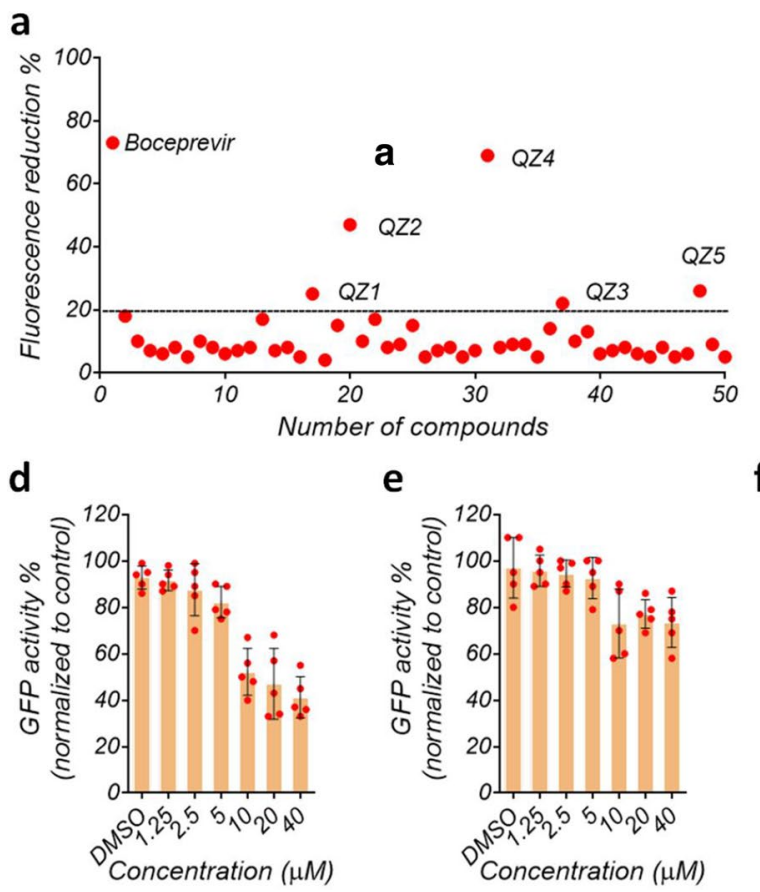

Fig. 4 Validation of GFP-split-3CLpro screening protocol using a small molecule in-house library. a GFP-split-3CLpro protocol was evaluated by screening an in-house library of 50 small molecule compounds at $10 \mu \mathrm{M}$ concentration. b Boceprevir showed an $80 \%$ reduction in GFP fluorescent activity at $40 \mu \mathrm{M}$, suggesting potent inhibi- protease activity, as presented in Fig. 4c, d, e, g. Among quinazoline derivatives, the compound QZ4 caused a considerable reduction in the GFP fluorescence intensity (Fig. 4f). We sought to calculate the $\mathrm{EC}_{50}$ of this compound by applying increasing concentrations of the inhibitor for $48 \mathrm{~h}$. The results revealed that the QZ4 compound, [3-(5-methoxy-2-hydroxy benzylidene amino)-2(5-methoxy-2-hydroxyphenyl)-2,3-dihydro quinazoline-4 $(1 \mathrm{H})$ one] reduced the GFP fluorescence intensity at an $\mathrm{EC}_{50}$ of $6.5 \mu \mathrm{M}$, suggesting potential inhibition against 3CLpro activity with $50 \%$ cytotoxic concentration $\left(\mathrm{CC}_{50}\right)$ more than $100 \mu \mathrm{M}$ at $48 \mathrm{~h}$ (Fig. 5a, b). Furthermore, we measured the $\mathrm{EC}_{50}$ value of the reference compound boceprevir, which is approximately $5.2 \mu \mathrm{M}$ at $48 \mathrm{~h}$ (Fig. $5 \mathrm{~d}$ ). The $\mathrm{EC}_{50}$ value of boceprevir is close to the $\mathrm{EC}_{50}$ of this compound measured by FRET-based enzymatic assay $(4.1 \mu \mathrm{M})$ [39], taking into account compound bioavailability in the cell-based assay.

\section{Structure-Antiviral Activity Relationship}

We further performed a molecular docking study to illustrate the binding of the QZ4 compound to SARS-CoV-2 main protease 3CLpro (Fig. 6). The X-ray crystal structure of 3CLpro (PDB ID: 6w63.pdb) was downloaded from Protein Databank, and we obtained the 3D structure of b

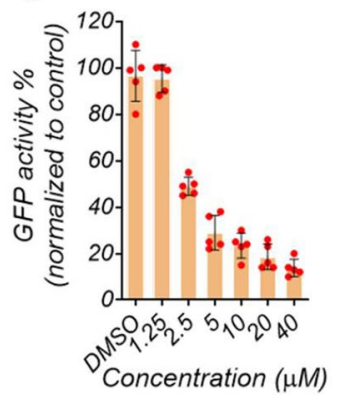

f

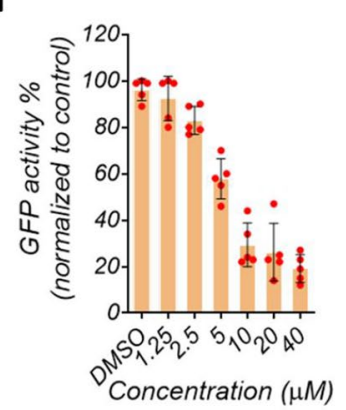

c

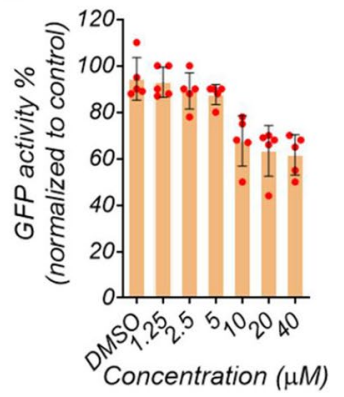

g

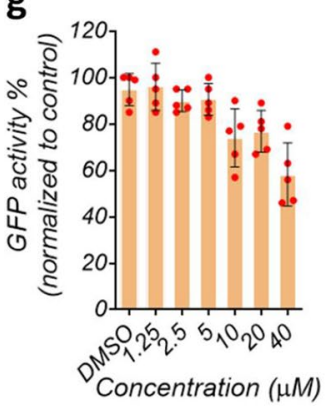

tion against SARS-CoV-2 main protease. Quinazoline derivatives: c QZ1; d QZ2; e QZ3; g QZ5 showed 20-50\% inhibition to viral protease while f QZ4 showed approximately $80 \%$ inhibition at $40 \mu \mathrm{M}$ $(n=5$ replicates $)$ 
Fig. 5 The inhibition potential of quinazoline derivatives QZ4 to SARS-CoV-2 main protease 3CLpro. a QZ4 compound, [3-(5-methoxy-2-hydroxy benzylidene amino)-2(5-methoxy2-hydroxyphenyl)-2,3-dihydro quinazoline-4(1H)-one]. b

The increasing concentrations of QZ4 showed considerable reduction in the GFP fluorescence intensity over the time c The reduction in GFP intensities indicates that the $\mathrm{EC}_{50}$ of QZ4 is approximately $6.5 \mu \mathrm{M}$ suggesting potential inhibition against 3CLpro activity with $50 \%$ cytotoxic concentration $\left(C C_{50}\right)$ more than $100 \mu \mathrm{M}$ at $48 \mathrm{~h}$. d $E C_{50}$ of boceprevir is approximately $5.2 \mu \mathrm{M}$ at $48 \mathrm{~h}$ $(n=3$ replicates $)$ a<smiles>COc1ccc(O)c(/C=N/N2C(=O)c3ccccc3NC2c2cc(OC)ccc2O)c1</smiles>

Quinazoline derivative QZ4

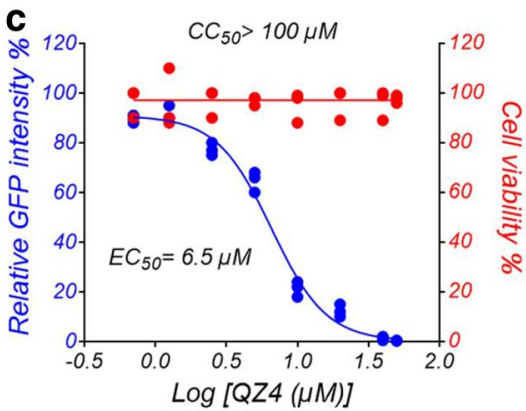

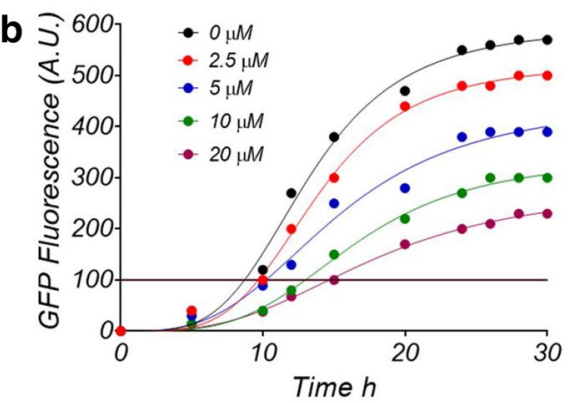

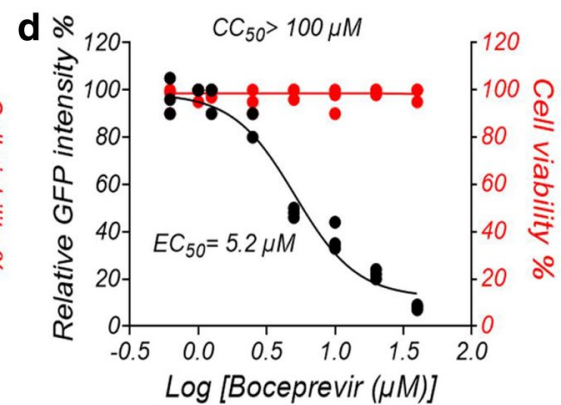

the QZ4 compound from PubChem. The results showed that the compound binds to the 3CLpro catalytic site with docking energy $-10.8 \mathrm{kcal} / \mathrm{mol}$. The QZ4 binds to the 3CLpro by three hydrogen bonds with Gln 189, Gln192, and Arg 188.. We described previously the synthesis of the bioactive quinazoline derivatives [40]. Quinazoline compounds showed potent kinase inhibition via phenyl group that allows favorable interaction with the target into the kinase domain 41 .

Furthermore, some kinase inhibitors have antiviral potential due to their activity against host cell kinases required for virus replication, and therefore, it was considered for drug repurposing against SARS-CoV-2 replication [42]. In this study, the quinazoline scaffold structure contains two active groups (R1 and R2) that contribute to its biological activity. Substitution of the two methoxyphenyl groups at R1 sites resulted in a considerable reduction in inhibition potencies of QZ4 compound to virus replication (Table 1). This study suggests a new class of viral protease inhibitors derived from quinazoline compounds that worth further investigation.

We do not expect the host cell proteases cleave the 3CLpro cleavage site because 3CLpro cleaves after a glutamine residue, and no human host-cell proteases are known with this substrate specificity [43, 44], reducing the non-specific cleavage of our GFP-designed construct. Our published data showed a practical implementation of split-GFP complementation assay to measure protein translocation from ER-to-cytosol [22]. Besides, viral 3CLpro and PLpro are conserved among coronaviruses, and the protease inhibitors could have a broad spectrum against different coronaviruses
[45]. Our published data also showed that protease assays are viable in identifying protease inhibitors virus replication such as HCV [27], DENV [28-36], and ZIKV [37, 38].

\section{Conclusion}

In this study, we developed a novel cell lines model for highthroughput screening (HTS) to identify inhibitors against SARS-CoV-2 protease based on split-GFP complementation. This method significantly enhances the safety, throughput, and reproducibility of antiviral screening. Besides, it helps shorten the time of screening drugs and provides the real-time activity of tested compounds and insight into compound toxicity. Most recently published studies of designing antiviral therapeutics against 3CLpro and PLpro depend on the in silico design and virtual screening without actual validation. Our cell-based protease assay will help validate the in silico designed inhibitors without using the infectious virus. Using this assay, we identified a new class of viral protease inhibitors derived from quinazoline compounds that worth further in vitro and in vivo validation.

\section{Methods}

\section{Construction of the Expression Cassettes}

Standard PCR was used to amplify the two GFP fragments, $\beta$-strand $1-9$ and $\beta$-strand $10-11$. The ten amino acids linker and cleavage sites of 3CLpro and E5/K5 amino 
Fig. 6 Molecular docking conformations of QZ4 compound to SARS-CoV-2 main protease 3CLpro. The X-ray crystal structure of 3CLpro (PDB ID: 6w63.pdb) was downloaded from Protein Databank, and the 3D structure of QZ4 ligand was downloaded from PubChem. The molecular docking between the optimized QZ4 and the 3CLpro receptor was performed using AutoDock Vina Version 2.0. Yellow: 3CLpro; CPK: ligand; magenta: reported binding site. The compound binds to the 3CLpro active site with docking energy $-10.8 \mathrm{kcal} /$ mol, by generating three hydrogen bonds with Gln 189, Gln192, and Arg 188 (Color figure online)
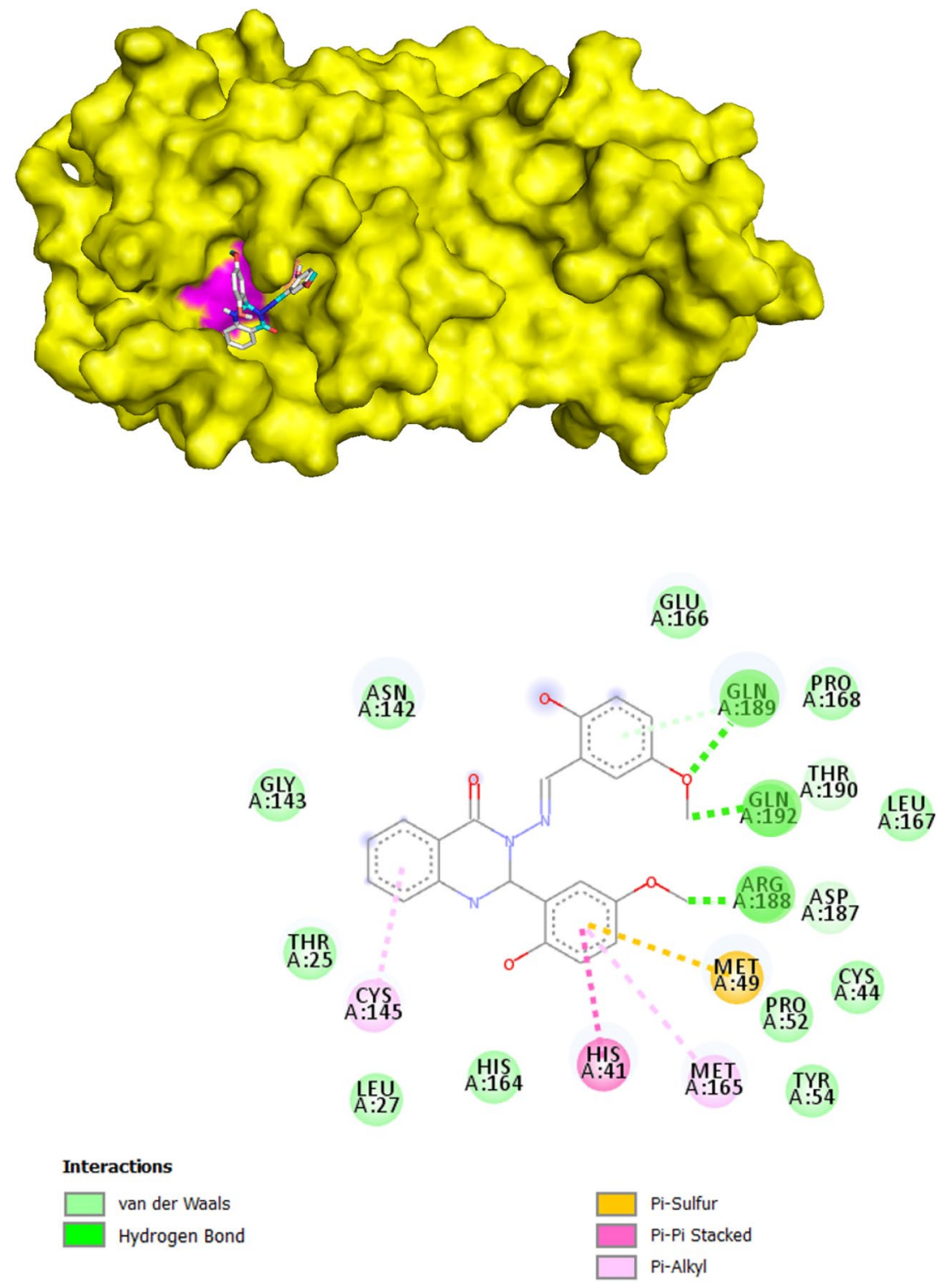

acid sequences were inserted into the GFP construct using overlap-extension PCR, as we described previously [26]. The purified DNA of GFP constructs and 3CLpro (GenBank code: MN908947.3, ORF1ab polyprotein residues 3264-3569,) were sequenced for any mutations, and the intact DNA fragments were cloned in pGEM®-T cloning vector (Cat.\# A1360, Promega), amplified in the E. coli, retrieved and sub-cloned in pcDNA3.1 mammalian expression vector (Cat.\# V79020, ThermoFisher). The HEK293T cells (ATCC) were co-transfected with the recombinant pcDNA3.1 plasmids using Lipofectamine 2000 (Cat.\# 11668-019, Invitrogen).

\section{Assay Optimization}

The cell-based assay was optimized for a 96-well plate. Assay conditions were optimized including, seeding cell density $\left(2 \times 10^{4}\right.$ cell/well), FBS concentration $(1.5 \%)$ in Dulbecco's modified Eagle medium (DMEM, Gibco) containing $1 \times$ GlutaMAX (Gibco), $1 \mathrm{mM}$ sodium pyruvate (Gibco), and $1 \times$ antibiotic-antimycotic solution (Gibco). Cells tolerance to the solvent used for the compounds (DMSO 0.1\%), in presence and absence of potential 3CLpro inhibitors. The HEK293T cells co-expressing split-GFP construct and SARS-CoV-2 3CLpro were cultured in 96-well black and clear-bottom plates (Cat.\# 07-200-625, fisher scientific) at $2 \times 10^{4}$ cells/well overnight. GFP fluorescence intensities were measured using Tecan F200 Pro multimode microplate reader at excitation $488 \mathrm{~nm}$ and emission $525 \mathrm{~nm}$ at different time points, and GFP expression in HEK293T cells was acquired by the fluorescence microscopy. 
Table 1 Scaffold structure of quinazoline compounds and structure-antiviral activity using GFP-split-3CLpro assay<smiles>[R2]c1cc([R2])c(O)c(/C=N/N2C(=O)c3ccccc3NC2c2cc([R2])cc([R2])c2O)c1</smiles>

\begin{tabular}{|c|c|c|c|c|c|c|c|}
\hline Compound code & Name & Formula & $M W$ & $R 1$ & $R 2$ & $I C_{50}(\mu \mathrm{M})$ & $C C_{50}(\mu \mathrm{M})$ \\
\hline QZ1 & $\begin{array}{l}\text { 3-(5-Bromo-2-hydroxybenzylideneamino)-2-(5-bromo- } \\
\text { 2-hydroxyphenyl)-2,3-dihydroquinazoline-4 (1H)-one }\end{array}$ & $\mathrm{C}_{21} \mathrm{H}_{15} \mathrm{~N}_{3} \mathrm{O}_{3} \mathrm{Br}_{2}$ & 517.17 & $\mathrm{Br}$ & $\mathrm{H}$ & $>40$ & $>100$ \\
\hline QZ2 & $\begin{array}{l}\text { 3-[(5-Chloro-2-hydroxy-benzylidene)-amino]-2-(5- } \\
\text { chloro-2-hydroxy-phenyl)-2,3-dihydroquinazoline- } \\
\text { 4(1H)-one }\end{array}$ & $\mathrm{C}_{21} \mathrm{H}_{15} \mathrm{~N}_{3} \mathrm{O}_{3} \mathrm{Cl}_{2}$ & 428.27 & $\mathrm{Cl}$ & $\mathrm{H}$ & 10 & $>100$ \\
\hline QZ3 & $\begin{array}{l}\text { 3-(5-Bromo-2-hydroxy-3-methoxybenzyl ideneamino)- } \\
\text { 2-(5-bromo-2-hydroxy-3-methoxyphenyl)-2,3-dihy- } \\
\text { droquinazoline-4(1H)-one }\end{array}$ & $\mathrm{C}_{23} \mathrm{H}_{19} \mathrm{Br}_{2} \mathrm{~N}_{3} \mathrm{O}_{5}$ & 576.97 & $\mathrm{Br}$ & $\mathrm{OCH} 3$ & $>40$ & $>100$ \\
\hline QZ4 & $\begin{array}{l}\text { 3-(5-Methoxy-2-hydroxybenzylideneamino)-2(5-meth- } \\
\text { oxy-2-hydroxyphenyl)-2,3-dihydroquinazoline-4(1H)- } \\
\text { one }\end{array}$ & $\mathrm{C}_{23} \mathrm{H}_{21} \mathrm{~N}_{3} \mathrm{O}_{5}$ & 419.43 & $\mathrm{OCH} 3$ & $\mathrm{H}$ & 6.5 & $>100$ \\
\hline QZ5 & $\begin{array}{l}\text { 3-(5-Nitro-2-hydroxybenzylideneamino)-2(5-nitro- } \\
\text { 2-hydroxyphenyl)-2,3-dihydroquinazoline-4(1H)-one }\end{array}$ & $\mathrm{C}_{21} \mathrm{H}_{15} \mathrm{~N}_{5} \mathrm{O}_{7}$ & 449.37 & $\mathrm{NO} 2$ & $\mathrm{H}$ & $>40$ & $>100$ \\
\hline
\end{tabular}

\section{Assay Validation By Screening Small Molecule Library}

A small in-house library was screened by treating cells with the compounds prepared in DMSO at $10 \mu \mathrm{M}$ concentration for $48 \mathrm{~h}$. We used boceprevir (Cas \# 394730600, Sigma) as a positive control that showed activity against SARS-COV-2 3CLpro [39]. The experiments were run on three occasions to identify the assay's hit rate, the reproducibility of the assay, and the false negative and false positive hit rates in the assay. At the endpoint of the split-GFP-3CLpro assay, we measure the compound cytotoxicity by applying 20/well of the MTT solution (CellTiter 96® AQueous, Promega) and incubating the cells for $4 \mathrm{~h}$ at $37{ }^{\circ} \mathrm{C}$ and $5 \% \mathrm{CO}_{2}$. The absorbance was measured at $490 \mathrm{~nm}$ using a 96-well plate reader.

\section{Molecular Docking}

The X-ray crystal structure of 3CLpro (PDB ID: 6w63. pdb) was downloaded from Protein Databank and minimized using the steepest descent algorithm in the GROMACS version 2020.1 with OPLSAA force field to the convergence of force less than $1000.0 \mathrm{~kJ} / \mathrm{mol} / \mathrm{nm}$. The 3D structure of QZ4 ligand was downloaded from PubChem and optimized using Gaussian09 software applying the density functional theory (DFT) calculations with B3LYP 6-31G(d) basis set. Molecular docking between the optimized QZ4 and the 3CLpro receptor was performed using AutoDock Vina Version 2.0. The molecular rendering was performed using PyMOL 1.3 (TM) 2010 Schrodinger, LLC, and the 2-D diagram, which was computed using Discovery Studio 4.5 Client to analyze the molecular interactions of docked conformations.

\section{Cell Viability}

The MTT assay was used to measure compounds cytotoxicity by applying 20/well of the MTT solution (CellTiter 96® AQueous, Promega) and incubating the cells for $4 \mathrm{~h}$ at $37{ }^{\circ} \mathrm{C}$ and $5 \% \mathrm{CO}_{2}$. The absorbance was measured at $490 \mathrm{~nm}$ using a $96-$ well plate reader.

Acknowledgments This study was supported by the Institut Pengurusan dan Pemantauan Penyelidikan, University of Malaya, TRGS Grant (TR001B-2014B).

\section{Compliance with Ethical Standards}

Conflict of interest The authors declare that they have no conflict of interest with the contents of this article. 


\section{References}

1. Rothan, H. A., \& Byrareddy, S. N. (2020). The epidemiology and pathogenesis of coronavirus disease (COVID-19) outbreak. Journal of Autoimmunity, 109, 102433.

2. Rothan, H. A., Acharya, A., Reid, S. P., Kumar, M., \& Byrareddy, S. N. (2020). Molecular aspects of COVID-19 differential pathogenesis. Pathogens, 9, 538.

3. Ouassou, H., Kharchoufa, L., Bouhrim, M., Daoudi, N. E., Imtara, H., et al. (2020). The pathogenesis of coronavirus disease 2019 (COVID-19): Evaluation and prevention. Journal of Immunology Research, 2020, 1357983.

4. Chan, J. F., Zhang, A. J., Yuan, S., Poon, V. K., Chan, C. C., et al. (2020). Simulation of the clinical and pathological manifestations of coronavirus disease 2019 (COVID-19) in golden Syrian hamster model: Implications for disease pathogenesis and transmissibility. Clinical Infectious Diseases. https://doi.org/10.1093/cid/ ciaa325.

5. Rothan, H. A., Stone, S., Natekar, J., Kumari, P., Arora, K., et al. (2020). The FDA-approved gold drug auranofin inhibits novel coronavirus (SARS-COV-2) replication and attenuates inflammation in human cells. Virology, 547, 7-11.

6. Farne, H., Kumar, K., Ritchie, A. I., Finney, L. J., Johnston, S. L., et al. (2020). Repurposing existing drugs for the treatment of COVID-19. Annals of the American Thoracic Society. https://doi. org/10.1513/AnnalsATS.202005-566FR.

7. Tufan, A., AvanogluGuler, A., \& Matucci-Cerinic, M. (2020). COVID-19, immune system response, hyperinflammation and repurposing antirheumatic drugs. Turkish Journal of Medical Sciences, 50, 620-632.

8. Korber, B., Fischer, W. M., Gnanakaran, S., Yoon, H., Theiler, J., et al. (2020). Tracking changes in SARS-CoV-2 spike: Evidence that D614G increases infectivity of the covid-19 virus. Cell. https ://doi.org/10.1016/j.cell.2020.06.043.

9. Kozlovskaya, L., Piniaeva, A., Ignatyev, G., Selivanov, A., Shishova, A., et al. (2020). Isolation and phylogenetic analysis of SARS-CoV-2 variants collected in Russia during COVID-19 outbreak. International Journal of Infectious Diseases. https://doi. org/10.1016/j.ijid.2020.07.024.

10 Weisblum, Y., Schmidt, F., Zhang, F., DaSilva, J., Poston, D., et al. (2020). Escape from neutralizing antibodies by SARS-CoV-2 spike protein variants. bioRxiv. https://doi. org/10.1101/2020.07.21.214759.

11. Taboada, B., Vazquez-Perez, J. A., Munoz Medina, J. E., Ramos Cervantes, P., Escalera-Zamudio, M., et al. (2020). Genomic analysis of early SARS-CoV-2 variants introduced in Mexico. Journal of Virology. https://doi.org/10.1128/JVI.01056-20.

12 Poterico, J. A., \& Mestanza, O. (2020). Genetic variants and source of introduction of SARS-CoV-2 in South America. Journal of Medical Virology. https://doi.org/10.1002/jmv.26001.

13. Lau, S. Y., Wang, P., Mok, B. W., Zhang, A. J., Chu, H., et al. (2020). Attenuated SARS-CoV-2 variants with deletions at the S1/S2 junction. Emerging Microbes and Infections, 9, 837-842.

14. Baez-Santos, Y. M., St John, S. E., \& Mesecar, A. D. (2015). The SARS-coronavirus papain-like protease: Structure, function and inhibition by designed antiviral compounds. Antiviral Research, $115,21-38$.

15. Mahmud, S., Uddin, M. A. R., Zaman, M., Sujon, K. M., Rahman, M. E., et al. (2020). Molecular docking and dynamics study of natural compound for potential inhibition of main protease of SARS-CoV-2. Journal of Biomolecular Structure and Dynamics. https://doi.org/10.1080/07391102.2020.1796808.

16. Jo, S., Kim, S., Shin, D. H., \& Kim, M. S. (2020). Inhibition of SARS-CoV 3CL protease by flavonoids. Journal of Enzyme Inhibition and Medicinal Chemistry, 35, 145-151.
17. Kumar, V., Tan, K. P., Wang, Y. M., Lin, S. W., \& Liang, P. H. (2016). Identification, synthesis and evaluation of SARS-CoV and MERS-CoV 3C-like protease inhibitors. Bioorganic and Medicinal Chemistry, 24, 3035-3042.

18. Lin, C. W., Lin, K. H., Hsieh, T. H., Shiu, S. Y., \& Li, J. Y. (2006). Severe acute respiratory syndrome coronavirus 3C-like proteaseinduced apoptosis. FEMS Immunology and Medical Microbiology, 46, 375-380.

19. Grum-Tokars, V., Ratia, K., Begaye, A., Baker, S. C., \& Mesecar, A. D. (2008). Evaluating the 3C-like protease activity of SARScoronavirus: Recommendations for standardized assays for drug discovery. Virus Research, 133, 63-73.

20. Anand, K., Palm, G. J., Mesters, J. R., Siddell, S. G., Ziebuhr, J., et al. (2002). Structure of coronavirus main proteinase reveals combination of a chymotrypsin fold with an extra alpha-helical domain. EMBO Journal, 21, 3213-3224.

21. Hegyi, A., \& Ziebuhr, J. (2002). Conservation of substrate specificities among coronavirus main proteases. Journal of General Virology, 83, 595-599.

22. Ruan, J., Rothan, H. A., Zhong, Y., Yan, W., Henderson, M. J., et al. (2019). A small molecule inhibitor of ER-to-cytosol protein dislocation exhibits anti-dengue and anti-Zika virus activity. Scientific Reports, 9, 10901.

23. Zhang, Q., Schepis, A., Huang, H., Yang, J., Ma, W., et al. (2019). Designing a green fluorogenic protease reporter by flipping a beta strand of GFP for imaging apoptosis in animals. Journal of the American Chemical Society, 141, 4526-4530.

24. To, T. L., Schepis, A., Ruiz-Gonzalez, R., Zhang, Q., Yu, D., et al. (2016). Rational design of a GFP-based fluorogeniccaspase reporter for imaging apoptosis in vivo. Cell Chemical Biology, 23, $875-882$.

25. Cabantous, S., Nguyen, H. B., Pedelacq, J. D., Koraichi, F., Chaudhary, A., et al. (2013). A new protein-protein interaction sensor based on tripartite split-GFP association. Scientific Reports, 3, 2854.

26. Rothan, H. A., Teh, S. H., Haron, K., \& Mohamed, Z. (2012). A comparative study on the expression, purification and functional characterization of human adiponectin in Pichia pastoris and Escherichia coli. International Journal of Molecular Sciences, $13,3549-3562$.

27. Abdulrahman, A. Y., Rothan, H. A., Rashid, N. N., et al. (2017). Identification of peptide leads to inhibit hepatitis $\mathrm{C}$ virus: Inhibitory effect of plectasin peptide against hepatitis $\mathrm{C}$ serine protease. International Journal of Peptide Research and Therapeutics, 23 , 163-170. https://doi.org/10.1007/s10989-016-9544-6.

28. Abdulrahman, A. Y., Rothan, H. A., Khazali, A. S., Teoh, T. C., Daher, A. M., et al. (2019). Synthetic peptide optimization improves the inhibition of dengue NS2B-NS3 protease and dengue replication in vitro. ActaVirologica, 63, 278-285.

29. Rothan, H. A., Zulqarnain, M., Ammar, Y. A., Tan, E. C., Rahman, N. A., et al. (2014). Screening of antiviral activities in medicinal plants extracts against dengue virus using dengue NS2B-NS3 protease assay. Tropical Biomedicine, 31, 286-296.

30. Rothan, H. A., Mohamed, Z., Paydar, M., Rahman, N. A., \& Yusof, R. (2014). Inhibitory effect of doxycycline against dengue virus replication in vitro. Archives of Virology, 159, 711-718.

31. Rothan, H. A., Bahrani, H., Rahman, N. A., \& Yusof, R. (2014). Identification of natural antimicrobial agents to treat dengue infection: In vitro analysis of latarcin peptide activity against dengue virus. BMC Microbiology, 14, 140.

32. Rothan, H. A., Bahrani, H., Mohamed, Z., Abd Rahman, N., \& Yusof, R. (2014). Fusion of protegrin-1 and plectasin to MAP30 shows significant inhibition activity against dengue virus replication. PLOS ONE, 9, e94561.

33. Rothan, H. A., Mohamed, Z., Suhaeb, A. M., Rahman, N. A., \& Yusof, R. (2013). Antiviral cationic peptides as a strategy for 
innovation in global health therapeutics for dengue virus: High yield production of the biologically active recombinant plectasin peptide. OMICS: A Journal of Integrative Biology, 17, 560-567.

34. Rothan, H. A., Buckle, M. J., Ammar, Y. A., Mohammadjavad, P., Shatrah, O., et al. (2013). Study the antiviral activity of some derivatives of tetracycline and non-steroid anti inflammatory drugs towards dengue virus. Tropical Biomedicine, 30, 681-690.

35. Rothan, H. A., Han, H. C., Ramasamy, T. S., Othman, S., Rahman, N. A., et al. (2012). Inhibition of dengue NS2B-NS3 protease and viral replication in Vero cells by recombinant retrocyclin-1. BMC Infectious Diseases, 12, 314.

36. Rothan, H. A., Abdulrahman, A. Y., Sasikumer, P. G., Othman, S., Rahman, N. A., et al. (2012). Protegrin-1 inhibits dengue NS2BNS3 serine protease and viral replication in MK2 cells. Journal of Biomedicine and Biotechnology, 2012, 251482.

37. Rothan, H. A., Abdulrahman, A. Y., Khazali, A. S., Nor Rashid, N., Chong, T. T., et al. (2019). Carnosine exhibits significant antiviral activity against Dengue and Zika virus. Journal of Peptide Science, 25, e3196.

38. Abdulrahman, A. Y., Khazali, A. S., Teoh, T. C., et al. (2019). Novel peptides inhibit zika NS2B-NS3 serine protease and virus replication in human hepatic cell line. International Journal of Peptide Research and Therapeutics, 25, 1659-1668. https://doi. org/10.1007/s10989-019-09808-4.

39. Ma, C., Sacco, M. D., Hurst, B., Townsend, J. A., Hu, Y., et al. (2020). Boceprevir, GC-376, and calpain inhibitors II, XII inhibit SARS-CoV-2 viral replication by targeting the viral main protease. Cell Research, 30, 678-692.

40. Rothan, H. A., Amini, E., Faraj, F. L., Golpich, M., Teoh, T. C., et al. (2017). NMDA receptor antagonism with novel indolyl,
2-(1,1-Dimethyl-1,3-dihydro-benzo[e]indol-2-ylidene)-malonaldehyde, reduces seizures duration in a rat model of epilepsy. Scientific Reports, 7, 45540.

41. Conconi, M. T., Marzaro, G., Urbani, L., Zanusso, I., Di Liddo, R., et al. (2013). Quinazoline-based multi-tyrosine kinase inhibitors: Synthesis, modeling, antitumor and antiangiogenic properties. European Journal of Medicinal Chemistry, 67, 373-383.

42. Weisberg, E., Parent, A., Yang, P. L., Sattler, M., Liu, Q., et al. (2020). Repurposing of kinase inhibitors for treatment of COVID19. Pharmaceutical Research, 37, 167.

43. Zhang, L., Lin, D., Kusov, Y., Nian, Y., Ma, Q., et al. (2020). Alpha-ketoamides as broad-spectrum inhibitors of coronavirus and enterovirus replication: Structure-based design, synthesis, and activity assessment. Journal of Medicinal Chemistry, 63, $4562-4578$.

44. Hilgenfeld, R. (2014). From SARS to MERS: Crystallographic studies on coronaviral proteases enable antiviral drug design. FEBS Journal, 281, 4085-4096.

45 Wrapp, D., Wang, N., Corbett, K. S., Goldsmith, J. A., Hsieh, C. L., et al. (2020). Cryo-EM structure of the 2019-nCoV spike in the prefusion conformation. Science. https://doi.org/10.1126/scien ce.abb2507.

Publisher's Note Springer Nature remains neutral with regard to jurisdictional claims in published maps and institutional affiliations. 